\title{
Psychological characteristics of women with climacteric age
}

\section{Belokrylova1,2, N. Garganeeva1,2, V. Nikitina ${ }^{1}$, I. Belokrylov¹, E. Epanchintseva ${ }^{1}$ \\ ${ }^{1}$ Mental Health Research Institute, Tomsk National Research Medical Center, Russian Academy of Sciences, Tomsk, Russia \\ ${ }^{2}$ Federal State Budgetary Educational Institution of Higher Education "Siberian State Medical University" of Ministry of Healthcare of the Russian Federation, Tomsk, Russia.}

Objective was to study the psychological well-being of women in menopause.

Materials and Methods: 117 women enrolled in a psychiatric clinic with non-psychotic mental disorders and who provided informed consent to participate in the study were examined. Used methods: clinical, psychopathological, psychological, statistical. Verification of the mental state was carried out in accordance with the ICD-10 diagnostic criteria. The Ryff's Scales of Psychological Well-being (adjusted version); the Taylor Manifest Anxiety Scale; the Kupperman menopausal index (Kupperman H.S., 1953); TAS-26 were used.

Results: Three groups were examined: women in the premenopausal state (48; mean age $-45.75 \pm 4.02$ years) entered group 1, patients with the onset of menopause up to 53 years $(51 ; 55.82 \pm 4.2$ years), group 3 - with the onset of menopause after 53 years (18; $58.27 \pm 2.94$ years). Neurotic, stress-related and somatoform disorders were observed respectively in $89.6 \%, 64.7 \%, 50 \%$ (Figure 1 ).

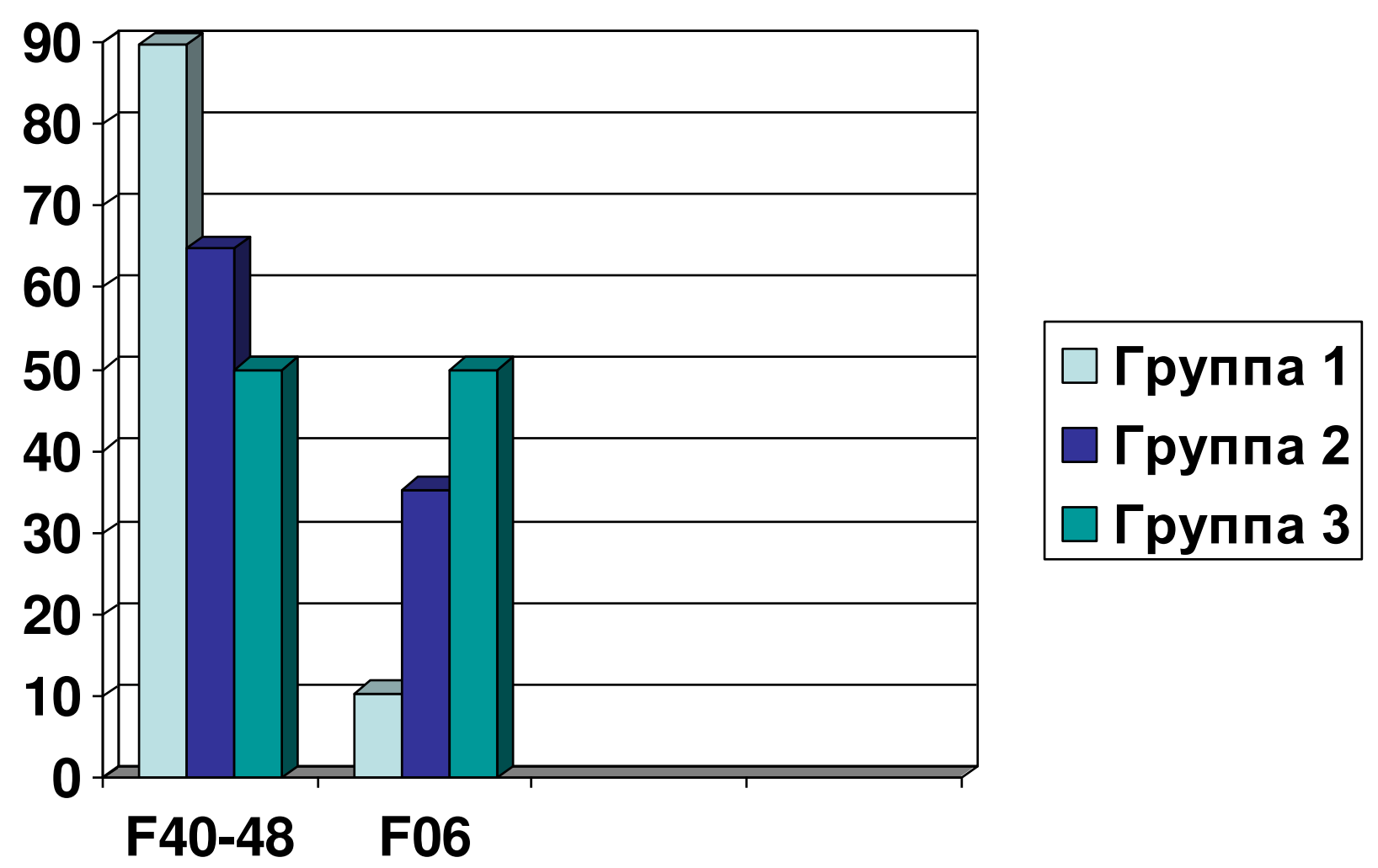

Figure 1. The structure of non-psychotic mental disorders in three groups of examined women: group 1 - female patients in the of pre-menopause; group 2 female patients with beginning of menopause before 53 years; group 3 female patients with beginning of the menopause after 53 years.

F06 - Organic non-psychotic disorders;

F40-48 - Neurotic, stress-related and somatoform disorders

In other cases, organic non-psychotic disorders were diagnosed. Statistically significant differences between groups 1 and 2 regarding "Personal growth" scale were revealed: higher rates were observed in premenopausal women (Table 1).
Table 1. Indices on the scales "Personal Growth"," SelfAcceptance", "Psychological Well-Being" in three groups of the examined women $\left(\mathrm{Me}\left(\mathrm{Q}_{1}-\mathrm{Q}_{3}\right)\right.$

\begin{tabular}{|c|c|c|c|}
\hline Scales & $\begin{array}{c}\text { Group 1, } \\
\mathrm{n}=48\end{array}$ & $\begin{array}{c}\text { Group } 2, \\
n=51\end{array}$ & $\begin{array}{c}\text { Group } 3 \\
n=18\end{array}$ \\
\hline \multirow[t]{2}{*}{ "Personal Growth" } & $58,0(53,5-64,0)^{*}$ & $54,0(49,0-62,0)^{*}$ & $56,5(51,0-64,0)$ \\
\hline & \multicolumn{2}{|c|}{$\begin{array}{l}\mathrm{N}_{1-2}=0,037580 ; \quad \mathrm{U}=927,000 \\
\mathrm{Z}=2,07942\end{array}$} & \\
\hline "Self-Acceptance" & $55,0(49,0-61,0)$ & $54,0(48,0-60,0)$ & $48,0(45,0-61,0)$ \\
\hline $\begin{array}{l}\text { "Psychological Well- } \\
\text { Being" }\end{array}$ & $343,0(316,5-361,5)$ & $\begin{array}{l}329,0(309,0- \\
370,0)\end{array}$ & $\begin{array}{l}344,5(299,0- \\
369,0)\end{array}$ \\
\hline
\end{tabular}

Negative correlations were found between the general indicator "Psychological Well-Being" and indicators on the "SelfAcceptance" scale with menopausal index, level of alexithymia and anxiety, and indicator of stress tolerance.

Level of alexithymia was significantly higher in group 2 (71.0(62,0-79,0) points) vs. group 1 (66.0 (59.5-75.5) points) ( $p$ $=0.003 ; U=922.500 ; Z=-2.11092)$. The higher the indices of alexithymia were, the lower the indices on the scale "Personal Growth" and "Self-acceptance" were. In addition to that, negative correlations between the level of anxiety and indices on the scale "Self-Acceptance" $(R=-0.52 ; p=0.000000)$ and on the scale "Personal Growth" $(R=-0,32 ; p=0,000532)$.

A negative correlation was found between menopausal index and indicators on the "Personal Growth" scale $(R=-0.26 ; p=$ $0.004)$, and indices on the scale "Self-Acceptance $(R=-0.35 ; p$ $=0.000106$ ).

In the total group $43.6 \%$ of female patients had low indices on the scale "Personal Growth" (Table 2).

Table 2. Frequency of low indices on the scales "Personal Growth", "Self-Acceptance", "Psychological Well-Being" in the total group of examined women $(n=117)$

\begin{tabular}{|l|c|c|c|c|}
\hline \multirow{2}{*}{ Scales } & \multicolumn{2}{|c|}{$\begin{array}{l}\text { Number of patients with low } \\
\text { indices on the scales }\end{array}$} & \multicolumn{2}{|c|}{$\begin{array}{l}\text { Number of patients with low } \\
\text { indices on three scales }\end{array}$} \\
\cline { 2 - 3 } & Abs. & $\%$ & Abs. & $\%$ \\
\hline "Personal Growth" & 51 & 43.6 & & \multirow{2}{*}{25} \\
\hline "Self-Acceptance" & 42 & 35.9 & 25 & \\
\hline $\begin{array}{l}\text { "Psychological Well- } \\
\text { Being" }\end{array}$ & 25 & 21.4 & & \\
\hline
\end{tabular}

A quarter of patients showed low scores on the scales "Personal Growth", "Self-Acceptance" and "Autonomy", despite the presence of purpose in life and the ability to establish positive ties with others. Thus, the ontogenetic crisis of menopausal age actualizes the problems of personal growth and mental health, forming the need for psychiatric and psychotherapeutic care. 